\title{
PERFORMANCE ANALYSIS OF DIFFERENT ANODE MATERIALS OF A DOUBLE CHAMBERED MICROBIAL FUEL CELL
}

\author{
Abdullah Al Moinee and Nahid Sanzida* \\ Department of Chemical Engineering, Bangladesh University of Engineering and Technology, \\ Dhaka, Bangladesh
}

\begin{abstract}
Microbial fuel cells (MFCs) are bio-electrochemical systems (BES) that can oxidize and convert biodegradable wastes directly into electricity via microbial metabolism. Since the oxidation half-cell of an MFC consists of the biodegradable electrolyte and anode, the selection of the right anode materials is essential to optimize the performance of MFCs. Anode acts as the governing support for the growth of biofilm to transfer the electrons. In general, anode materials must have a reasonable surface area for bacterial growth, good conduction, excellent biocompatibility, chemical stability, high mechanical strength, and low cost. In this work, graphite bar, aluminum foil, and carbon cloth were tested as an anode. The comparative performances of them were analyzed in a double chambered MFC containing industrial wastewater with respect to the power density and waste removal efficiency of MFCs. The carbon cloth anode provided better output than graphite bar and aluminum foil. The 10 days of batch operation for carbon cloth anode resulted in a maximum of $672.34 \mathrm{mWm}^{-3}$ power density and $52.20 \%$ removal of chemical oxygen demand (COD).
\end{abstract}

Keywords: Microbial Fuel Cell, Oxidation, Anode, Power Density, COD, Carbon Cloth

\section{Introduction}

Microbial fuel cells (MFC) is one of the cuttingedge technologies that provide a sustainable process for renewable energy and wastewater treatment. MFCs work by utilizing bacterial metabolism and cellular respiration to drive the oxidation of the substrate (such as organic wastes from industries, agriculture, or sewage) at anode and reduction of an oxidant (usually $\mathrm{O}_{2}$ ) at cathode. Bioelectricity is produced through MFC in an oxygen-deficient environment of anode where a series of microorganisms convert the complex wastes to electrons through a cascade of enzymes in a bioelectrochemical process. The anode electrode plays an important role in the performance and cost of MFCs [1]. Even with the notable improvements in power density, the large-scale application of MFCs is still limited due to the low power generation and high cost [2]. To take this cutting-edge technology from laboratory-scale research to commercial applications, the cost and the performance of these systems need to be optimized further.

The anode material design has attracted an enormous number of studies for this optimization over the past decade. The selection of the proper electrode material is crucial for the performance of MFCs in terms of bacterial adhesion, electron transfer, and electrochemical efficiency. Carbonaceous materials, graphite rods and graphite - brushes, carbon cloth, carbon paper, carbon felt, and reticulated vitreous carbons are widely used in MFCs due to their higher electrical conductivity, specific surface area, biocompatibility, chemical stability and low cost [3].

In general, electrodes of microbial fuel cells (MFCs) should possess a rough anode surface that facilitates the adhesion of bacteria; hence, the power density of a rough anode is significantly higher than that of a smooth anode. The porosity and surface area ensures the accessibility of microorganisms to the electrode. The reducing and oxidizing environment in an MFC may lead to the swelling and decomposition of the materials. The high surface roughness increases the durability of the material while it might increase the chances of fouling, thus may decrease the long-term performance of the MFC. Therefore, the material for electrodes should be durable as well as stable in an acidic and basic environment. Because microorganisms are inoculated directly on the surface of the anodes, the biocompatibility of the anode electrode with a biocatalyst is a critical factor that determines the MFC power generation. The biocompatibility of an electrode allows the microorganisms to adhere and spread over the electrode surface and form an electroactive biofilm. To control fouling and poisoning, a high void volume of the electrode and large surface area per volume (e.g. carbonaceous electrode) is needed [4]. Recent research has focused on carbonaceous or stainless steel mesh electrodes applicable for MFCs. 
This effectively replaces the precious metal anodes due to their abundant sources, cost efficiency, prompt conductivity, and chemical inertness [1].

In this work different anode material was applied to evaluate the performance of a double chambered microbial fuel cell. This research work emphasized the anodic removal of chromium to highlight the microbial mechanism for removing chromium from textile wastewater (TWW).

\section{Methodology}

In the anaerobic ambiance of anode chamber the metabolic activity of the microorganisms produces electron and proton which had advantages over the aerobic media. So, the electron can be utilized for the generation of electricity and removal of chromium while protons migrate through the salt bridge and produce water by combining with available oxygen at aerobic chamber of cathode. Alternatively, aeration produces carbon di-oxide and water in anode chamber instead of electrons, protons, and carbon dioxide. Besides, the aeration would decrease the thickness of biofilms around anode. So, this is essential for the chamber of anode to be anaerobic to get feasible results. Glucose was used as nutrients in anode chamber for the stable growth of microbes [5]. In aerobic ambiance of cathode chamber, the oxidizing agent $\mathrm{O}_{2}$ produces water by combining with hydrogen ions migrated through salt bridge. The oxidizing agent was reduced by receiving the electrons. The bio-electrochemical process was harnessed by the aerobic environment of cathode. The environment maintained the concentration of dissolved oxygen to trigger the redox reaction. Eventually, the $\mathrm{pH}$ of the electrolytes was maintained properly. To evaluate the cell performance, the following parameters were calculated,

Maximum power density $=$

Maximum power generated during a batch operation working volume of microbial fuel cell

where, maximum power $=$ maximum voltage $\times$ maximum current

$$
\begin{aligned}
& \% \text { COD removal }=\frac{\mathrm{COD}_{\text {initial }}-\mathrm{COD}_{\text {final }}}{\mathrm{COD}_{\text {initial }}} \times 100 \% \\
& \% \mathrm{Cr} \text { removal }=\frac{\mathrm{Cr}_{\text {initial }}-\mathrm{Cr}_{\text {final }}}{\mathrm{C}_{\text {initial }}} \times 100 \%
\end{aligned}
$$

and

$$
\text { Coulombic Efficiency, } \mathrm{C}_{\mathrm{E}}=\frac{8 \int_{0}^{\mathrm{t}} I d t}{\mathrm{~F} V \Delta \mathrm{COD}}
$$

where, $\mathrm{F}=$ Faraday's constant $96500 \mathrm{C} / \mathrm{mol}$, V= volume of the liquid in anode compartment $=1.2 \mathrm{~L}$, I is current flow in $\mathrm{A}, \mathrm{t}$ is in second, and $\triangle \mathrm{COD}$ is in $\mathrm{g} / \mathrm{L}$.

\section{Material and Methods}

Different anode materials were investigated for their performance, e.g. carbon cloth. graphite bar, and aluminum foil electrode. Figure 1 (a) to 1(c) show the electrodes. The dimension of the carbon cloth was $8.0 \mathrm{~cm} \times 7.0 \mathrm{~cm} \times 0.04 \mathrm{~cm}$.

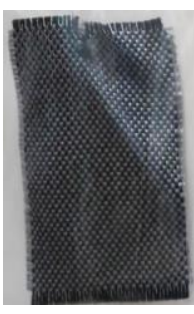

a

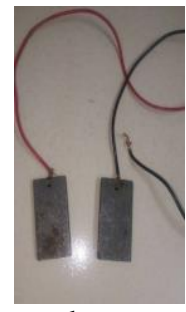

b

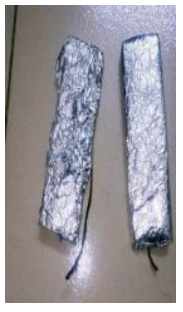

Figure 1: Different types of anode employed in MFCs (a) Raw carbon cloth, (b) Graphite bar electrode, (c) Aluminum foil electrode

During some of the experiments graphite electrodes were used as both anode and cathode to evaluate the performance of the cell. Each of the graphite electrode had a dimension of $5.0 \mathrm{~cm} \times 2.5$ $\mathrm{cm} \times 0.5 \mathrm{~cm}$. Aluminum foil was also used as anode and cathode to evaluate the performance of the cell. Each of the Al-foil electrode had a dimension of 5.0 $\mathrm{cm} \times 2.5 \mathrm{~cm} \times 0.5 \mathrm{~cm}$. Table 1 shows the different combinations of cell components (e.g. electrodes) for different operational cases for developing MFCs.

\begin{tabular}{|c|c|c|c|c|c|}
\hline$\underset{\dot{0}}{\dot{0}}$ & 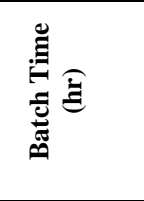 & 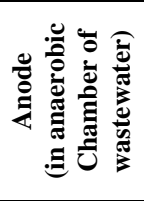 & 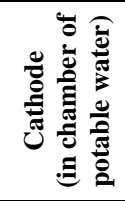 & 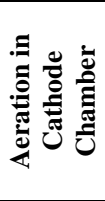 & 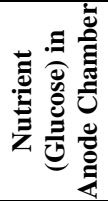 \\
\hline 1 & \multirow{7}{*}{$\begin{array}{c}12 \\
\text { (Industry 1) }\end{array}$} & & & $\mathrm{x}$ & $\mathrm{x}$ \\
\hline 2 & & Graphite & Graphite & $\checkmark$ & $\mathrm{x}$ \\
\hline 3 & & & & $\sqrt{ }$ & $\sqrt{ }$ \\
\hline 4 & & $\mathrm{Al}-$ Foil & Graphite & \multirow{6}{*}{ ( } & \multirow{6}{*}{$\checkmark$} \\
\hline 5 & & $\mathrm{Al}$ - Foil & $\mathrm{Al}$ - Foil & & \\
\hline 6 & & $\begin{array}{l}\text { Carbon } \\
\text { Cloth }\end{array}$ & Graphite & & \\
\hline 7 & & $\begin{array}{l}\text { Carbon } \\
\text { Cloth }\end{array}$ & $\mathrm{Al}$ - Foil & & \\
\hline 8 & $\begin{array}{c}240 \\
(\mathrm{SWW})\end{array}$ & $\begin{array}{c}\text { Carbon } \\
\text { Cloth }\end{array}$ & Graphite & & \\
\hline 9 & $\begin{array}{c}240 \\
\text { (TWW, } \\
\text { Industry } \\
2 \text { ) }\end{array}$ & $\begin{array}{c}\text { Carbon } \\
\text { Cloth }\end{array}$ & $\begin{array}{c}\mathrm{Al}-\text { Foil } \\
\text { over } \\
\text { Graphite }\end{array}$ & & \\
\hline
\end{tabular}

Table 1:

Combinations of cell components for different operational cases

A double-chambered microbial fuel cell (DC-MFC) was constructed for experimental operations. Each chamber was made of Perspex (Polymethyl methacrylate) with a dimension of 10 $\mathrm{cm} \times 10 \mathrm{~cm} \times 15 \mathrm{~cm}$. Microbial oxidation reaction occurs in the anode chamber containing wastewater and reduction occurs in the cathode chamber. The 
anode chamber was maintained at anaerobic environment. An air pump was used for maintaining aerobic condition in cathode. The external circuit connected anode and cathode by insulated copper wire and a multi-meter. The current and voltage was logged by the multi-meter periodically for batch operation in MFC. A salt bridge of saturated sodium chloride $(\mathrm{NaCl})$ connected the chambers. The pipe fittings of salt bridge were made of stainless steel (SS). All the experiments were operated at room temperature at around $25^{\circ} \mathrm{C}$ and atmospheric pressure. Figure 2 shows the laboratory set-up of the MFC.
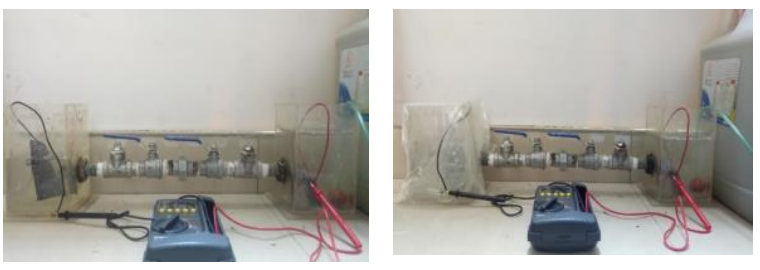

Figure 2: Complete experimental setup of microbial fuel cell

\section{Results and Discussions}

The voltage and current output were logged by batch operation for 12 hours for Industry 1 and 240 hours (10 days) for synthetic wastewater (SWW) and textile wastewater (TWW, Industry 2) system. According to the availability of wastewater, initially seven experiments were conducted utilizing the wastewater of Industry 1 . Table 2 shows the relative results of cell operations.

Table 2:

Relative results of cell operations

\begin{tabular}{|c|c|c|c|c|c|c|}
\hline $\begin{array}{l}\dot{0} \\
\dot{z} \\
\dot{x} \\
\dot{x}\end{array}$ & 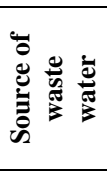 & 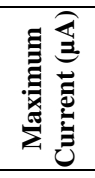 & 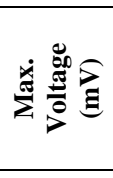 & 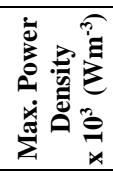 & 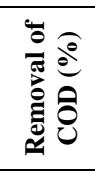 & 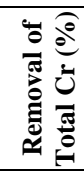 \\
\hline 1 & \multirow{7}{*}{ 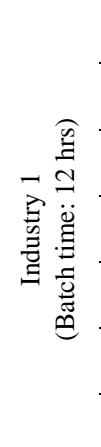 } & 81.2 & 358.2 & 24.73 & 19.21 & - \\
\hline 2 & & 139.2 & 438.5 & 50.86 & 21.68 & - \\
\hline 3 & & 151.9 & 483.0 & 63.55 & 31.26 & - \\
\hline 4 & & 194.7 & 736.0 & 114.41 & 30.07 & - \\
\hline 5 & & 239.4 & 866.6 & 172.89 & 34.51 & - \\
\hline 6 & & 256.9 & 930.5 & 174.29 & 45.42 & - \\
\hline 7 & & 332.8 & 1205.4 & 334.3 & 43.50 & - \\
\hline 8 & SWW & 397.1 & 659.3 & 218.17 & 46.67 & 33.33 \\
\hline 9 & 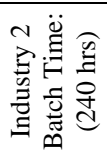 & 733.4 & 1100.1 & 672.34 & 52.20 & 53.75 \\
\hline
\end{tabular}

The first seven experiments helped in developing an efficient setup for cell operation to remove chromium from textile wastewater (TWW, Industry 2). The finalized setup was then applied to Exp. 8 and Exp. 9 for treating SWW and TWW respectively considering the higher toxicity of Chromium $(\mathrm{Cr})$.

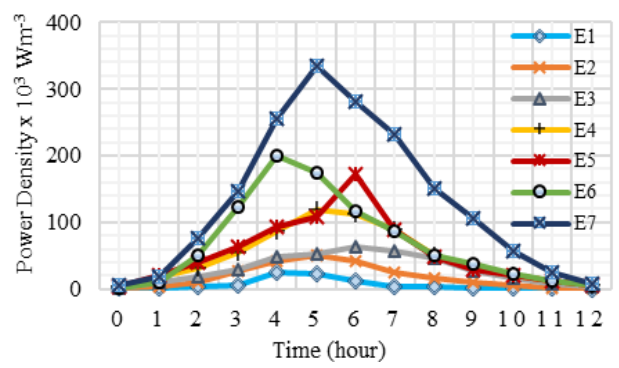

Figure 3: Power density for 12 hours of batch operation from Experiment no. 1 to Experiment no. 7 (Industry 1)

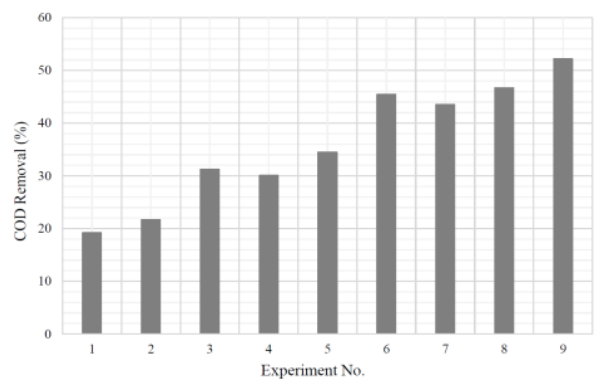

Figure 4: Removal percentage of COD

Figure 3 shows that each of the seven experiments of Industry 1 were conducted for a batch duration of 12 hours. Except for Exp. 1 the cathode compartment was aerated for the other experiments. It is evident that the presence of air in cathode chamber increased the amount of electricity generation as well as the \% COD removal. Figure 3 and Figure 4 shows that the maximum power density of Exp. 1 is $24.73 \mathrm{mWm}^{-3}$ with $19.21 \%$ COD removal in absence of aeration and nutrient when the maximum power density for Exp. 2 is $50.86 \mathrm{mWm}^{-3}$ with $21.68 \%$ COD removal in presence of aeration but no nutrient was added to the anaerobic chamber of anode. Therefore, aeration in cathode is an important parameter to enhance cell performance. In this regard, it is important to mention that aeration in anode stops the production of electrons because the organics react with available oxygen to produce carbon di-oxide and water instead of carbon di-oxide, protons, and electrons. Moreover, the aeration creates a shear disturbance around the anode for the biofilm [1]. Nutrients are added in microbial fuel cell (MFC) as the substrate for organic wastes so that the microbes can receive available organics to degrade for generating their survival energy (ATP). The active presence of microbes is important to get uninterrupted electron transfer between the half-cells. Nutrient was added to the anode compartment of all other experiments except Exp. 1 and Exp. 2 Nutrient provides excess substrates for the microbes. Therefore, the microbes can receive 
necessary organics to degrade and produce more electrons for continuing the treatment process. Figure 3 shows that five experiments from Exp. 3 to Exp. 7 generated more electricity in presence of nutrient than Exp. 1 and Exp. 2 where no nutrient was applied. In this work, glucose was added as a nutrient (the source of carbon) from Exp. 3 to Exp 9. The required concentration of carbon source was maintained at a concentration that was greater than $10^{-2} \mathrm{~mol} / \mathrm{L}$ for the stable growth of microbes [5].

Graphite electrode was used for both anode and cathode from Exp. 1 to Exp. $3 \mathrm{Al}$ - Foil anode and graphite cathode was used in Exp. $4 \mathrm{Al}$ - Foil electrode was used for both anode and cathode in Exp. 5. Figure 3 and Figure 4 show that Exp. 4 generated more electricity than Experiment no. 3 as anode was replaced by an $\mathrm{Al}$ - Foil electrode because the conductivity of $\mathrm{Al}$ - Foil electrode is more than graphite electrode [6] Exp 4 resulted in $30.07 \%$ COD removal. With a maximum power density that was increased from of $63.55 \mathrm{mWm}^{-3}$ (Exp 3) to 119.41 $\mathrm{mWm}^{-3}(\operatorname{Exp} 4)$. Exp. 5 used $\mathrm{Al}$ - Foil for both anode and cathode. Figure 3 and 4 show that power density was increased from $119.41 \mathrm{mWm}^{-3}$ to $172.89 \mathrm{mWm}^{-3}$ with $34.51 \%$ COD removal. For developing an efficient setup of MFC, Exp. 5 provided better results than Exp 4. Here, Al-Foil electrodes can provide better conductivity and surface area so that the chemical oxygen demand (COD) can be removed more efficiently. Figure 3 shows that Exp. 6 generated a maximum power density of 174.29 $\mathrm{mWm}^{-3}$ with $45.42 \%$ COD removal. In this regard, Figure 3 and 4 show that Exp. 7 generated a maximum power density of $334.3 \mathrm{mWm}^{-3}$ voltage with $43.50 \%$ COD removal. Therefore, it is observed that, MFC provided better results with carbon cloth electrodes than graphite or $\mathrm{Al}$ - Foil electrodes because carbon cloth has high electrical conductivity, lower resistance and chemical stability [7]. The nanostructures of carbon cloth (anode) provide higher porosity and surface area than graphite electrodes and aluminum foil. Therefore, it can provide more suitable positions specifically for the adsorption of contaminants (e.g. chromium) through microbial metabolism [3]. The growth of microbes and electron transport system require considerable surface areas to make the flow continuous. The significance of comparing different types of electrodes is that it helps to find the workable, electrically efficient electrode (e.g. carbon cloth) for removing chromium by microbial metabolism, easily available, and costeffective electrode.

Wastewater from Industry 1 was used in Exp. 1 7. The experimental setups of these seven experiments provide significant comparison for developing an efficient MFC configuration. Carbon cloth anode, Al-Foil/graphite cathode, $\mathrm{NaCl}$ salt bridge, nutrient, and aeration made the most efficient combination for cell operation considering all experimental results. The electrolyte of anode chamber was synthetic wastewater (SWW) for Exp. 8 with carbon cloth anode and graphite cathode).

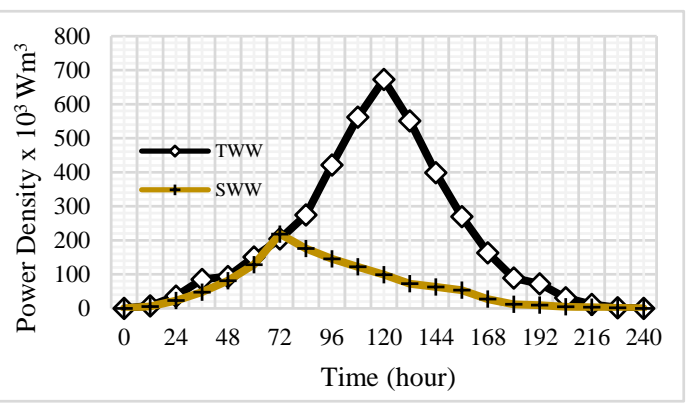

Figure 5: Power density for 10 days (240 hours) of batch operation for synthetic wastewater (SWW, Experiment no. 8) and textile wastewater (TWW, Experiment no. 9)

Figure 4 and 5 show that Exp. 8 obtained a maximum power density of $218.17 \mathrm{mWm}^{-3}$ at 72 hours with $46.67 \%$ COD removal. In Exp. 8, the initial concentration of total chromium was maintained at $0.03 \mathrm{mgL}-1$ (Table 5). In this case, the anaerobic chamber of carbon cloth anode was connected by the salt bridge of $\mathrm{NaCl}$ with the aerobic chamber of $\mathrm{Al}$ - Foil over Graphite cathode. The cathodic reaction can be improved by the use of catalytic-coated electrodes. In order to improve the performance of the cell the available electrodes were taken and $\mathrm{Al}$ - Foil was wrapped over graphite electrode (carbon rod). Aluminum foil gives not only a better performance than graphite due to higher conductivity [6] but also provides higher surface area according to the experimental analyses. Thus the artificial coating aids to increase the sustenance of the current towards a maximum value for providing electricity generation for a longer time. Figure 4 and 5 show in Exp. 9 that the efficient combination of cell for textile wastewater generated a maximum power density of $672.34 \mathrm{mWm}^{-3}$ at 120 hours with $52.20 \%$ COD removal. during the batch operation of 10 days (240 hours). The nine experiments eventually helped to develop and design an efficient cell which ultimately resulted in a feasible decision to select carbon cloth as anode. Consequently, the sustenance time of electron supply and power generation to reach the maximum value was increased. The increase in the sustenance time to reach a maximum eventually increases the removal percentage of COD and total chromium due to the treatment for a longer period.

Table 3 calculates the coulombic efficiency utilizing the electrical parameters of microbial fuel cell (MFC) and change of chemical oxygen demand (COD) in wastewater. Table 4 and 5 show the experimental data for removal percentage of COD and total chromium. Figure 4 represents the comparative removal percentage of COD for the 9 experiments to evaluate the cell performance in removing chromium from textile wastewater (TWW). 
Table 3:

Coulombic efficiency of microbial fuel cell in treating wastewater

\begin{tabular}{lcc}
\hline Experiment No. & 8 & 9 \\
\hline Source of wastewater & $\begin{array}{c}\text { Synthetic } \\
\text { wastewater } \\
(\mathrm{SWW})\end{array}$ & $\begin{array}{c}\text { Textile } \\
\text { wastewater } \\
(\mathrm{TWW})\end{array}$ \\
\hline Working volume, $\mathrm{V}(\mathrm{L})$ & \multicolumn{2}{c}{1.2} \\
\hline $\begin{array}{l}\text { Time to generate maximum } \\
\text { current, t }(\mathrm{s})\end{array}$ & $72 \times 3600$ & $120 \times 3600$ \\
\hline Maximum current, I $(\mu \mathrm{A})$ & 397.1 & 733.4 \\
\hline $\begin{array}{l}\text { Initial COD concentration, } \\
\mathrm{COD}_{\text {initial }}\left(\mathrm{mgL}^{-1}\right)\end{array}$ & 512 & 1544 \\
\hline $\begin{array}{l}\text { COD concentration at maximum } \\
\text { current generation, } \mathrm{COD}_{\mathrm{t}}\left(\mathrm{mgL}^{-1}\right)\end{array}$ & 409 & 1310 \\
\hline Coulombic Efficiency, $\mathrm{C}_{\mathrm{E}}(\%)$ & 6.90 & 9.35 \\
\hline
\end{tabular}

Table 4:

Experimental data for percentage of COD removal

\begin{tabular}{|c|c|c|c|c|}
\hline $\begin{array}{l}\dot{8} \\
\dot{z} \\
\dot{x}\end{array}$ & 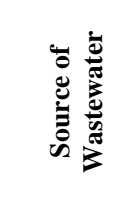 & 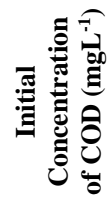 & = & 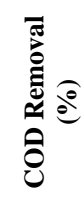 \\
\hline 1 & \multirow{7}{*}{ Industry 1} & 984 & 795 & 19.21 \\
\hline 2 & & 987 & 773 & 21.68 \\
\hline 3 & & 891 & 613 & 31.26 \\
\hline 4 & & 765 & 535 & 30.07 \\
\hline 5 & & 739 & 484 & 34.51 \\
\hline 6 & & 698 & 381 & 45.42 \\
\hline 7 & & 701 & 396 & 43.50 \\
\hline 8 & SWW & 512 & 273 & 46.67 \\
\hline 9 & $\begin{array}{c}\text { Industry } 2 \\
\text { (TWW) }\end{array}$ & 1544 & 738 & 52.20 \\
\hline
\end{tabular}

Table 5:

Experimental data for percentage removal of total chromium $(\mathrm{Cr})$

\begin{tabular}{|c|c|c|c|c|}
\hline $\begin{array}{l}\dot{0} \\
\dot{z} \\
\dot{x} \\
\dot{x}\end{array}$ & : & 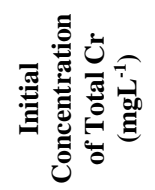 & 西产 & 焉总 \\
\hline $1-7$ & Industry 1 & 0 & 0 & - \\
\hline 8 & SWW & 0.030 & 0.020 & 33.33 \\
\hline 9 & TWW & 0.080 & 0.037 & 53.75 \\
\hline
\end{tabular}

SEM (scanning electron microscopy) characterizes the surface properties of electrodes. Figure 6 and Figure 7 present the sample SEM images of raw and treated carbon cloths. They show the electrodeposition of elements over the electrode. Figure 6 shows that the raw carbon cloth provided a homogeneous surface of woven fibre. Figure 7 shows addition and increase of mass percentage for different elements due to gradual addition of organics and metals from the wastewater. The surface of carbon cloth showed increase in roughness after 240 hours of batch operation for removing chromium from textile wastewater.

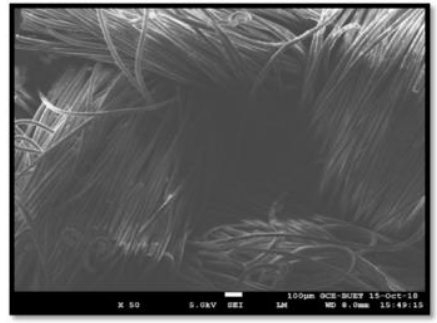

Figure 6: Sample SEM analyses of raw carbon cloth

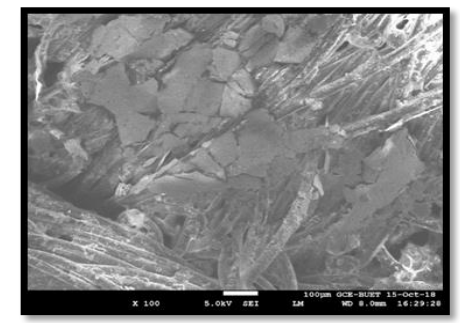

Figure 7: Sample SEM analyses of treated carbon cloth

The EDS (energy dispersive spectroscopy) X-ray detector measures the number of emitted X-rays versus energy $(\mathrm{keV})$. The energy of the $\mathrm{X}$-ray is characteristic of the chemical element from which the $\mathrm{X}$-ray is emitted [8] e.g. the X-ray photon emits 5.41 $\mathrm{keV}$ energy for chromium (Cr). The EDX analyses of raw and treated carbon cloths is conducted by selected certain positions on the SEM images. Investigations of the localized point are shown in Figure 8 and 9 . The mass percentage of chromium in raw carbon cloth (untreated) was found 0 at position 001 and 002 when position 004 (Figure 8) gave $0.16 \%$ of chromium for the emission of $5.41 \mathrm{keV}$ energy.

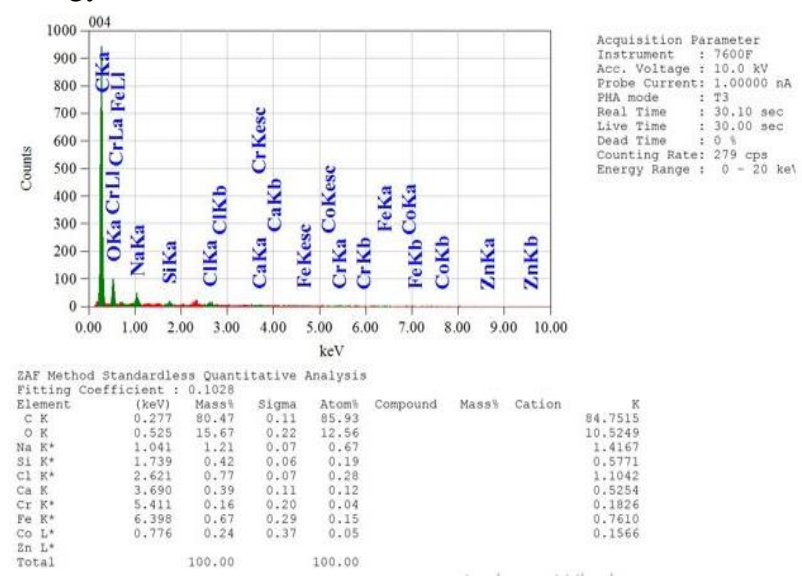

Figure 8: Sample EDX analyses of raw carbon cloth

Similarly, Figure 9 shows that the mass percentage of chromium for the treated carbon cloth of Textile Wastewater (TWW). The figure provides $1.29 \% \mathrm{Cr}$ at position 006 for the elemental emission of $5.41 \mathrm{keV}$ energy. By scanning the sample through a range of 2 Theta $\left({ }^{\circ}\right)$, possible diffraction directions of the target should be attained due to the random orientation of the material of concern [9]. 


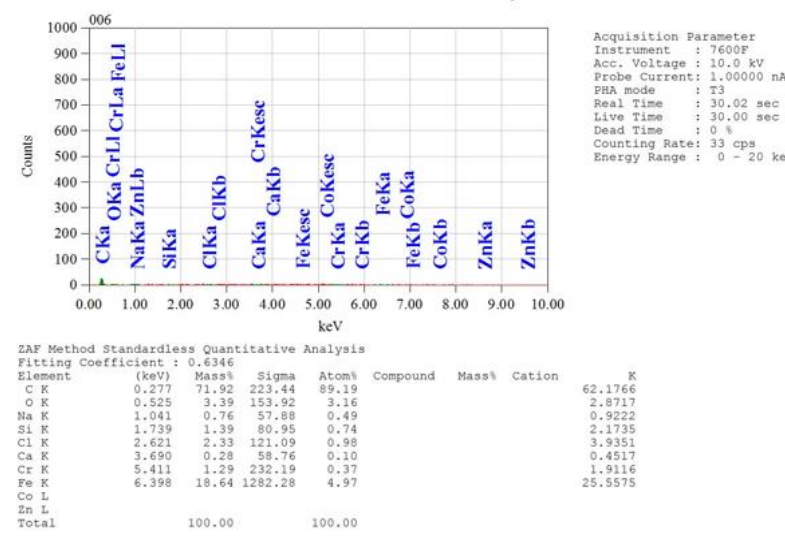

Figure 9: Sample EDX analyses of treated carbon cloth

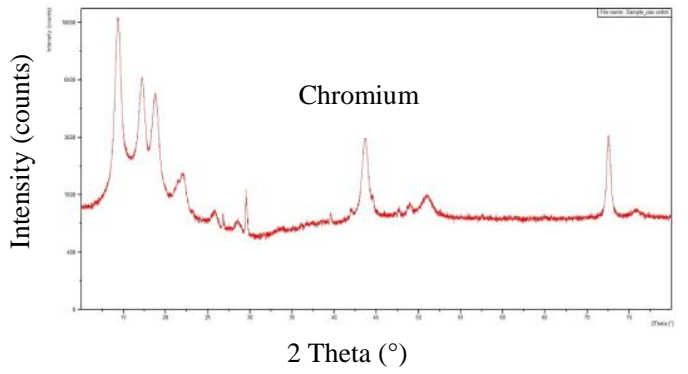

Figure 10: Sample XRD analyses of raw carbon cloth

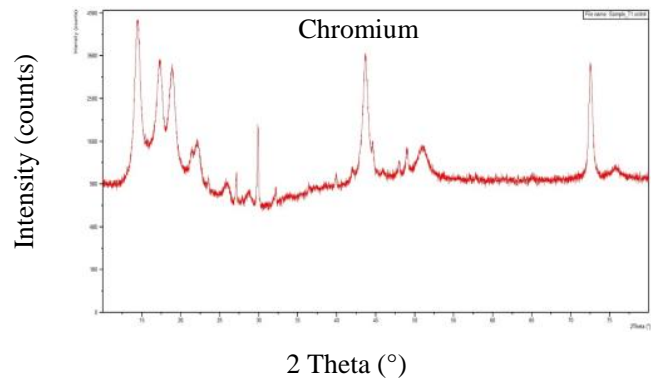

Figure 11: Sample XRD analyses of treated carbon cloth

The sample XRD patterns of raw and treated carbon cloths are shown in Figure 10 and Figure 11. The intensity i.e. count rate was 3600 for the peak of raw carbon cloth. It indicates the accumulation and crystallization of chromium $(\mathrm{Cr})$ because the higher and sharper diffraction peaks (Figure 11) at approximately $2 \theta=45^{\circ}$ corresponding to metallic nanocrystal of $\mathrm{Cr}[9]$.

\section{Conclusion}

This research work evidently presented the interactive effect and mechanism of microbial presence in removing chromium from textile wastewater. This work contributed not only to cathodic removal of chromium (metal) ions as electron acceptors in cathode but also to anodic removal of chromium (metal) ions at low concentrations which eventually confirmed the active metabolism (anaerobic) of microbes during cell operations. The performance of the laboratory scale double chambered Microbial Fuel Cell (MFC) was perpetually enhanced by comparative study and research on construction materials of electrodes. Consequently, the carbon cloth anode contributed to the cell performance efficiently which resulted in $53.75 \%$ removal of total chromium, $52.20 \%$ removal of COD, 9.35\% coulombic efficiency, and 672.34 $\mathrm{mWm}-3$ power density in the batch operation of 10 days. The analytical assessment of SEM - EDX and XRD provided the surface morphology, mass percentage, and elemental identification of chromium in the anode during the analyses. The cell had an advantage of working at ambient temperature and pressure that excluded the consideration of cost for employing external unit operations. Compared to conventional treatments, energy consumption is significantly reduced and this novel work recovered a maximum of $290.45 \mathrm{kJm}^{-3}$ energy from the cell operation.

\section{References}

[1] Das, D. (2018). Introduction. In Debabrara Das (Ed.), Microbial Fuel Cell: A bielectrochemical system that converts waste to watts (pp. 1 - 20). New Delhi, India: Capital Publishing Company

[2] Wei, J., Liang, P., \& Huang, X. (2011). Recent progress in electrodes for microbial fuel cells. Bioresource Technology, 102, 9335-9344. doi: 0.1016/j.biortech.2011.07.019

[3] Mustakeem. (2015). Electrode materials for microbial fuel cells: Nanomaterial approach. Materials for Renewable and Sustainable Energy, 4, p. 22. doi: 10.1007/s40243-015-0063-8

[4] Han, T. H., Sawant, S. Y., and Cho, M. H. (2018). Development of suitable anode materials for microbial fuel cells. In Debabrata Das (Ed.), Microbial Fuel Cell: A bielectrochemical system that converts waste to watts (pp. 101 - 124). New Delhi, India: Capital Publishing Company

[5] Shuler, M. L., and Kargi, F. (2002). The Basics of Biology: An Engineer's Perspective. Bioprocesss Engineeirng - Basic Concepts (pp. 49-52). New Jersey, USA: Pearson Education Incorporation

[6] Serway, A. R. (1998). Principles of Physics (p. 602). Fort Worth, Texas, USA: Sounders College Publication

[7] Uddin, I., Ahmer, F. M., and Asiri, A. M. (Eds.). (2019). Microbial fuel cells: Materials and applications (pp. 5374). Millersville, USA: Material Research Foundation

[8] Bergstrom, J. (2015). Experimental characterization techniques. Mechanics of Solid Polymers, pp. 19-114. doi: 10.1016/B978-0-323-31150-2.00002-9

[9] Ali, M. R., Nishikata, A., and Tsuru, T. (2001). Electrodeposition of cobalt-chromium alloys from cobalt chloride- $\mathrm{N}-(\mathrm{n}$ butyl) pyridinium chloride molten salt. Indian Journal of Chemical Technology, 8, pp. 44-50. doi: 10.1016/S0013-4686(96)00382-9

CBangladesh Uni. of Engg. \& Tech. 